\title{
Thai plants with high antioxidant levels, free radical scavenging activity, anti- tyrosinase and anti-collagenase activity
}

\author{
Moragot Chatatikun ${ }^{1}$ and Anchalee Chiabchalard ${ }^{2^{*}}$ (D)
}

\begin{abstract}
Background: Ultraviolet radiation from sunlight induces overproduction of reactive oxygen species (ROS) resulting in skin photoaging and hyperpigmentation disorders. Novel whitening and anti-wrinkle compounds from natural products have recently become of increasing interest. The purpose of this study was to find products that reduce ROS in 14 Thai plant extracts.

Methods: To determine total phenolic and flavonoid content, antioxidant activity, anti-tyrosinase activity and anticollagenase activity, we compared extracts of 14 Thai plants prepared using different solvents (petroleum ether, dichloromethane and ethanol). Antioxidant activities were determined by DPPH and ABTS assays.

Results: Total phenolic content of the 14 Thai plants extracts was found at the highest levels in ethanol followed by dichloromethane and petroleum ether extracts, respectively, while flavonoid content was normally found in the dichloromethane fraction. Scavenging activity ranged from 7 to 99\% scavenging as assessed by DPPH and ABTS assays. The ethanol leaf extract of Ardisia elliptica Thunb. had the highest phenolic content, antioxidant activity and collagenase inhibition, while Cassia alata (L.) Roxb. extract had the richest flavonoid content. Interestingly, three plants extracts, which were the ethanolic fractions of Annona squamosa L., Ardisia elliptica Thunb. and Senna alata (L.) Roxb., had high antioxidant content and activity, and significantly inhibited both tyrosinase and collagenase.

Conclusion: Our finding show that the ethanol fractions of Annona squamosa L., Ardisia elliptica Thunb. and Senna alata (L.) Roxb. show promise as potential ingredients for cosmetic products such as anti-wrinkle agents and skin whitening products.
\end{abstract}

Keywords: Ardisia elliptica Thunb., Antioxidant content, Scavenging activity, Anti-tyrosinase activity, Anti-collagenase activity

\section{Background}

Ultraviolet radiation (UVR) from sunlight is the most significant risk factor for nonmelanoma and melanoma skin cancers [1]. Overexposure to sunlight, in particular UVA and UVB, induces the overexpression of reactive oxygen species (ROS) which damage lipids, proteins and deoxyribonucleic acids. Collagen is the major foundation of the extracellular matrix in the dermis layer of the skin. Excessive ROS increases expression of collagenase, a protease that degrades collagen which can result in

\footnotetext{
* Correspondence: anchalee.c@chula.ac.th

${ }^{2}$ Department of Clinical Chemistry, Faculty of Allied Health Sciences,

Chulalongkorn University, Bangkok 10330, Thailand

Full list of author information is available at the end of the article
}

photoaging and wrinkling of the skin [2]. In addition, UV exposure induces melanin production resulting in hyperpigmentation. Tyrosinase is the key enzyme initiating skin pigmentation. Firstly, L-tyrosine is hydroxylated to form 3,4-dihidroxyphenylalanine (L-DOPA) by tyrosinase. Subsequently, L-DOPA is oxidized to DOPA quinone by tyrosinase. DOPA quinone is further converted to DOPA chrome that can be converted to 5,6-dihydroxyindole (DHI) or 5,6-dihydroxyindole-2-carboxylic acid (DHICA) [3]. The current treatments for skin aging involves hydroxyl acid to peel the epidermal layer, retinoids to reduce rough skin, and skin filler administered by injecting collagen into the skin. However, these treatments have adverse effects, such as hyperpigmentation, inflammation, cytotoxicity, 
irritation and bacterial infection [4]. The most popular skin whitening agent is hydroquinone, which inhibits tyrosinase, but its side effects include dermatitis, edema, allergic reactions and ochronosis [5]. Recently, researchers have focused on natural products that inhibit UV-induced ROS, suppress enzymes, and reduce melanin formation as alternatives to current treatments. For example, active phytocompounds, such as arbutin, aloesin, gentisic acid, flavonoids, hesperidin, licorice, niacinamide, yeast derivatives, and polyphenols, inhibit melanogenesis without cytotoxicity to melanocytes [6]. Thus, plants may reduce wrinkle formation and hyperpigmentation caused by sunlight exposure.

The aim of this study was to analyze 14 Thai plants extracted with three different solvents for their potential as anti-wrinkle and skin whitening ingredients. The quantity of antioxidant phenols and flavonoids was evaluated for a correlation with free radical scavenging activities, and anti-collagenase and anti-tyrosinase activities. The extracts had antioxidants that scavenged free radicals and inhibited enzymes involved in wrinkle and pigment formation. We identify Ardisia elliptica Thunb., Annona squamosa L. and Senna alata (L.) Roxb as very promising candidates for use in cosmetic products.

\section{Methods}

\section{Chemicals and reagents}

Folin Ciocalteu's phenol reagent, sodium carbonate $\left(\mathrm{Na}_{2} \mathrm{CO}_{3}\right)$, gallic acid, quercetin, $10 \%$ aluminium chloride, ethanol, 2, 2-diphenyl-1-picrylhydrazyl (DPPH), ascorbic acid, 2,2'-Azino-bis(3-ethylbenzthiazoline-6-sulphonic acid) (ABTS), potassium persulfate, kojic acid, mushroom tyrosinase (EC 1.14.18.1), 3,4-dihydroxy-L-phenylalanine (L-DOPA), N-[3-(2-furyl) acryloyl]-Leu-Gly-Pro-Ala
(FALGPA), collagenase from Clostridium histolyticum (EC 3.4.24.3), epigallocatechin gallate (EGCG), sodium chloride, calcium chloride and dimethyl sulfoxide (DMSO) were purchased from Sigma-Aldrich Chemical Co. (St. Louis, MO, USA). Petroleum ether, dichloromethane, absolute ethanol, methanol, disodium hydrogen phosphate and sodium dihydrogen phosphate were purchased from Merck (Darmstadt, Germany). All chemicals and reagents were analytical grade.

\section{Plant materials and extraction}

Thirteen species of Thai leaves were collected from the HRH Princess Sirindhorn Herb Garden, Rayong province, Thailand. Mangosteens were obtained from Chanthaburi province, Thailand. These plants were authenticated and deposited at the Herbarium, Department of Botany, Faculty of Science, Chulalongkorn University, Thailand. The scientific names, voucher numbers and plant parts are shown in Table 1. The plants were extracted by using the Soxhlet apparatus. In brief, $10 \mathrm{~g}$ of dried plant was extracted separately with petroleum ether, dichloromethane and ethanol. Solvents were removed using a vacuum rotary evaporator under reduced pressure using the MiVac Quattro concentrator. Concentrated samples were dissolved in DMSO at $100 \mathrm{mg} /$ $\mathrm{ml}$ and stored at $-20{ }^{\circ} \mathrm{C}$ until used. Yields of dry extracts are presented in Table 1 as $\% w / w$ dry plant materials.

\section{Determination of total phenolic content}

Total phenolic content of plant extracts was evaluated using the Folin-Ciocalteu method [7]. Briefly, $50 \mu \mathrm{l}$ of extracts at $1 \mathrm{mg} / \mathrm{ml}$ in distilled water was mixed with $50 \mu \mathrm{l}$ of $10 \%$ Folin-Ciocalteu reagent and $50 \mu \mathrm{l}$ of $0.1 \mathrm{M}$

Table 1 Extracts of 14 Thai plants and their yields based on weight

\begin{tabular}{|c|c|c|c|c|c|}
\hline \multirow{2}{*}{$\begin{array}{l}\text { Voucher } \\
\text { number }\end{array}$} & \multirow{2}{*}{$\begin{array}{l}\text { Parts } \\
\text { used }\end{array}$} & \multirow[t]{2}{*}{ Scientific name } & \multicolumn{3}{|l|}{ Yield \% (w/w) } \\
\hline & & & Petroleum ether & Dichloromethane & Ethanol \\
\hline A 015122 (BCU) & Leaf & Ardisia elliptica Thunb. & 19.89 & 3.25 & 31.11 \\
\hline A 015123 (BCU) & Leaf & Stemona curtisii Hook.f. & 7.55 & 4.10 & 6.34 \\
\hline A 015124 (BCU) & Leaf & Gynura pseudochina (L.) DC. & 8.00 & 2.76 & 3.79 \\
\hline A 015125 (BCU) & Leaf & Senna alata (L.) Roxb. & 5.84 & 3.52 & 7.63 \\
\hline A 015126 (BCU) & Leaf & Croton roxburghii N.P.Balakr & 7.50 & 4.82 & 8.17 \\
\hline A 015127 (BCU) & Leaf & Croton sublyratus Kurz & 7.33 & 4.03 & 3.32 \\
\hline A 015128 (BCU) & Leaf & Phyllanthus acidus (L.) Skeels & 9.70 & 2.86 & 4.20 \\
\hline A 015129 (BCU) & Leaf & Rhinacanthus nasutus (L.) Kurz & 4.43 & 2.86 & 5.35 \\
\hline A 015130 (BCU) & Leaf & Hibiscus mutabilis L. & 6.30 & 2.79 & 0.73 \\
\hline A 015131 (BCU) & Leaf & Streblus asper Lour. & 3.87 & 2.53 & 3.56 \\
\hline A 015132 (BCU) & Leaf & Annona squamosa $\mathrm{L}$. & 8.69 & 3.81 & 5.47 \\
\hline A 015133 (BCU) & Leaf & Datura metel L. & 6.44 & 4.13 & 14.15 \\
\hline A 015250 (BCU) & Leaf & Ipomoea pes-caprae (L.) R.br. & 6.38 & 4.50 & 3.98 \\
\hline A 015279 (BCU) & Pericarp & Garcinia mangostana Linn. & 4.94 & 11.07 & 18.64 \\
\hline
\end{tabular}


$\mathrm{Na}_{2} \mathrm{CO}_{3}$. The reaction mixture was incubated for $1 \mathrm{~h}$ at room temperature in the dark. Absorbance at $750 \mathrm{~nm}$ was measured with a microplate reader (Biotek, USA.). Gallic acid from 1.56 to $100 \mu \mathrm{g} / \mathrm{ml}$ was used as the standard. Total phenolic content of the extracts is expressed as mg gallic acid equivalents (GAE) per g dry plant material. All samples were analyzed in triplicate.

\section{Flavonoid content determination}

Total flavonoid content (TFC) was determined using the aluminium chloride $\left(\mathrm{AlCl}_{3}\right)$ colorimetric assay [7]. Briefly, $50 \mu \mathrm{l}$ of the extracts at $1 \mathrm{mg} / \mathrm{ml}$ in $80 \%$ ethanol was mixed with $50 \mu \mathrm{l}$ of $2 \% \mathrm{AlCl}_{3}$ solution in the well of a 96 wellplate. The plate was incubated for $15 \mathrm{~min}$ at room temperature. The absorbance at $435 \mathrm{~nm}$ was measured using a microplate reader. Quercetin from 1.56 to $100 \mu \mathrm{g} /$ $\mathrm{ml}$ served as a standard. Total flavonoid content is expressed as mg quercetin equivalents (QE) per g dry plant material. Samples were analyzed in triplicate.

\section{DPPH scavenging activity}

DPPH scavenging activity assay was performed as described by Yamasaki et al. [8]. DPPH solution was freshly prepared for each assay. Briefly, $100 \mu \mathrm{g} / \mathrm{ml}$ extracts or 1.56 to $100 \mu \mathrm{g} / \mathrm{ml}$ ascorbic acid standard in absolute methanol was mixed with $180 \mu \mathrm{l}$ of DPPH reagent in a 96 well-plate. The reaction mixture was incubated for $30 \mathrm{~min}$ at room temperature in the dark. Then, the absorbance at $517 \mathrm{~nm}$ was measured with a microplate reader. The experiments were undertaken in triplicate. The absorbance at $517 \mathrm{~nm}$ of $\mathrm{DPPH}$ was $0.70 \pm 0.02$, and decreased absorbance measured scavenging activity. The scavenging ability was calculated as scavenging activity $(\%)=100 \% \times\left[\left(\right.\right.$ 훤 $\mathrm{A}_{517}$ of control - 훷 $\mathrm{A}_{517}$ of sample)/ 훷 $\mathrm{A}_{517}$ of control]. Percentages of DPPH scavenging activity of the extracts were compared with those of ascorbic acid, and are expressed as mg vitamin $\mathrm{C}$ equivalent antioxidant capacity (VCEAC) per $g$ dry plant material. IC50 was determined from a graph of percent inhibition against concentration (from 0.78-100 $\mu \mathrm{g}$ / $\mathrm{ml}$ of each extract).

\section{ABTS scavenging activity}

ABTS free radical scavenging activity was performed as previously described [9]. The $\mathrm{ABTS}^{\circ+}$ working reagent was prepared by mixing $7 \mathrm{mM} \mathrm{ABTS}^{\circ}$ and $2.45 \mathrm{mM}$ potassium persulfate at 8:12 volume/volume ratio. The working solution was kept for 16 to $18 \mathrm{~h}$ at room temperature in the dark. The $\mathrm{ABTS}^{*+}$ solution was diluted with absolute ethanol to give an absorbance at $734 \mathrm{~nm}$ of $0.70 \pm 0.02$. Then, $100 \mu \mathrm{g} / \mathrm{ml}$ extracts or 1.56 to $100 \mu \mathrm{g} /$ $\mathrm{ml}$ ascorbic acid standard in absolute ethanol was added to $180 \mu \mathrm{l}$ of $\mathrm{ABTS}^{*+}$ working reagent in the wells of a 96 well plate. The plate was incubated for $45 \mathrm{~min}$ at room temperature, and absorbance was measured at $734 \mathrm{~nm}$.
Experiments were undertaken in triplicate. The scavenging ability was calculated as scavenging activity $(\%)=100 \times[($ 훤 $\mathrm{A}_{734}$ of control - 훤 $\mathrm{A}_{734}$ of sample)/ 훷 $\mathrm{A}_{734}$ of control]. The percentages of ABTS scavenging activity of the extracts were compared with those of ascorbic acid, and are presented as mg vitamin $\mathrm{C}$ equivalent antioxidant capacity (VCEAC) per g dry plant material. IC50 was determined from a graph of percent inhibition against concentration (from $15.62-1000 \mu \mathrm{g} / \mathrm{ml}$ of each extract).

\section{Determination of mushroom tyrosinase inhibition}

The dopachrome method was performed with slight modification [10]. Briefly, $20 \mu \mathrm{l}$ of plant extracts or DMSO (as control), $20 \mu \mathrm{l}$ of 203.3 units $/ \mathrm{ml}$ mushroom tyrosinase and $140 \mu \mathrm{l}$ of $20 \mathrm{mM}$ phosphate buffer at $\mathrm{pH} 6.8$ were pre-incubated for $10 \mathrm{~min}$ at $25{ }^{\circ} \mathrm{C}$. After pre-incubation, $20 \mu \mathrm{l}$ of $2.5 \mathrm{mM}$ L-DOPA was added and samples were then incubated for an additional $20 \mathrm{~min}$ at $25{ }^{\circ} \mathrm{C}$. The amount of dopachrome was measured at $492 \mathrm{~nm}$ with a microplate reader. Kojic acid (KA) served as a positive control for inhibition. The percent inhibition of tyrosinase activity (\%) was express as \% tyrosinase inhibition $=100 \times\left[\left(\right.\right.$ 훷 $\mathrm{A}_{492}$ of control 휯 $\mathrm{A}_{492}$ of sample)/ 휯 $\mathrm{A}_{492}$ of control]. The final concentrations of the extracts and kojic acid were 1 and $0.1 \mathrm{mg} / \mathrm{ml}$, respectively. IC50 was determined from a graph of percent tyrosinase inhibition against concentration (from $15.62-1000 \mu \mathrm{g} / \mathrm{ml}$ of each extract).

\section{Determination of collagenase inhibition}

Collagenase inhibition was determined by a previously described method [11]. Briefly, $40 \mu \mathrm{l}$ of collagenase from Clostridium histolyticum at $0.25 \mathrm{units} / \mathrm{ml}$ in $50 \mathrm{mM}$ Tricine buffer containing $10 \mathrm{mM} \mathrm{CaCl}$ and $400 \mathrm{mM} \mathrm{NaCl}$, and $10 \mu \mathrm{l}$ of $50 \mathrm{mM}$ Tricine buffer were mixed with $10 \mu \mathrm{l}$ of the extracts or DMSO (as control). Epigallocatechin gallate (EGCG) was used as a positive control. After a 15 -min incubation at room temperature, $50 \mu \mathrm{l}$ of $\mathrm{N}$ [3-(2-furyl)acryloyl]-Leu-Gly-Pro-Ala (FALGPA) was added. The absorbance was measured at $340 \mathrm{~nm}$ immediately and continually for $20 \mathrm{~min}$. Enzyme activity was evaluated by decreased absorbance during the time interval. The percent inhibition of collagenase activity was calculated as $100 \times$ [(Activity of control - Activity of sample)/ Activity of control]. Final concentrations of the extracts and epigallocatechin gallate were 1 and $0.1 \mathrm{mg} / \mathrm{ml}$, respectively. IC50 was determined from a graph of percent collagenase inhibition against concentration (from $15.62-1000 \mu \mathrm{g} / \mathrm{ml}$ of each extract).

\section{Statistical analyses}

All experiments were carried out in triplicate and results are expressed as mean \pm standard error. The correlation coefficiency $\left(R^{2}\right)$ between antioxidant contents and 
antioxidant activities was determined by using SigmaPlot version 12.2 software. Difference between two means was evaluated using Student's $t$-test. Differences were considered significant when the $P$-value was less than 0.05 .

\section{Results}

\section{Extraction yields}

Table 1 shows the scientific names, voucher numbers and plant parts of the 14 Thai plants used in this study. The percent yields of the extracts ranged from $0.73 \%$ to $31.11 \%$ by weight (Table 1 ). Ardisia elliptica Thunb. had the highest yield in the petroleum ether (19.89\%) and ethanol extracts (31.11\%), whereas Garcinia mangostana L. had the highest percent yield from dichloromethane extraction (11.07\%).

\section{Phenolic content of 14 Thai plants}

Therefore, total phenolic content in the plants was determined by the Folin-Ciocalteu method. The extracts had a wide range in the quantity of phenols as shown in Table 2, and values varied by 33 -fold among the extracts. Ardisia elliptica Thunb. had the highest phenol content in all three types of extracts, whereas the lowest phenolic content was present in the Stemona curtissi Hook.f. petroleum ether extract.

\section{Flavonoid content of 14 Thai plants}

Similar to phenols, total flavonoid content varied substantially among the plant species, ranging from $2.04 \pm 0.16$ to $31.38 \pm 0.81 \mathrm{mg}$ QE per g dry material (Table 2). In general, dichloromethane extraction yielded the highest flavonoid level compared with the other solvents. Of all extracts, the highest flavonoid quantity was found in the ethanol extract from Senna alata (L.) Roxb leaves (31.38 $\pm 0.81 \mathrm{mg}$ QE per $\mathrm{g}$ dry material). On the other hand, Ardisia elliptica Thunb. $(23.14 \pm 1.10 \mathrm{mg}$ QE per g dry material). had the richest flavonoid content in the dichloromethane fraction. Moreover, Ipomoea pes-caprae (L.) R.br. had the highest flavonoid content among the petroleum ether extracts (27.48 $\pm 2.59 \mathrm{mg}$ QE per g dry material). The lowest detectable flavonoid level was in the ethanol extract from Datura metel L. By stark contrast, flavonoids were not found in the petroleum ether and dichloromethane extracts from Stemona curtisii Hook.f., and petroleum ether extracts from Streblus asper Lour. and Phyllanthus acidus (L.) Skeels. Total flavonoid content did not correlate with total phenolic content $\left(R^{2}=0.0284\right.$, Fig. 1a).

\section{DPPH radical scavenging activity in different extracts from 14 Thai plants}

Free radical scavenging activity using DPPH as the indicator is a basic antioxidant assay [12]. As shown in Table 3, scavenging activities of the extracts varied greatly, ranging from $7.11 \pm 0.59 \%$ to $96.17 \pm 0.05 \%$. The Ardisia elliptica Thunb ethanol extract had the highest scavenging activity at $96 \%$. Moreover, the next strongest antioxidant activities (> 90\%) were observed in ethanol fractions from Stemona curtisii Hook.f., Annona squamosa L., Phyllanthus acidus (L.) Skeels. and Garcinia mangostana Linn. In terms of the other solvents, Ardisia elliptica Thunb, also had the richest scavenging activity among the petroleum ether fractions, and Garcinia mangostana L. had the highest antioxidant activity in the dichloromethane fractions. The lowest scavenging ability was detected in Croton sublyratus Kurz

Table 2 Total phenolic and flavonoid contents of 14 Thai plants obtained from different solvents

\begin{tabular}{|c|c|c|c|c|c|c|}
\hline \multirow[t]{2}{*}{ Extract } & \multicolumn{3}{|c|}{ Total phenolic content (mg GAE/g dry material) } & \multicolumn{3}{|c|}{ Total flavonoid content (mg QE/g dry material) } \\
\hline & Petroleum ether & Dichloromethane & Ethanol & Petroleum ether & Dichloromethane & Ethanol \\
\hline Annona squamosa $\mathrm{L}$. & $4.13 \pm 0.38$ & $9.26 \pm 0.29$ & $62.67 \pm 2.32$ & $8.91 \pm 0.77$ & $9.70 \pm 0.24$ & $12.99 \pm 0.65$ \\
\hline Ardisia elliptica Thunb & $22.26 \pm 1.77$ & $59.97 \pm 2.90$ & $84.00 \pm 6.23$ & $19.87 \pm 1.26$ & $23.14 \pm 1.10$ & $18.56 \pm 1.45$ \\
\hline Croton roxburghii N.P.Balakr & $3.57 \pm 0.25$ & $9.60 \pm 0.46$ & $19.41 \pm 0.81$ & $4.25 \pm 0.35$ & $12.34 \pm 0.29$ & $7.54 \pm 0.35$ \\
\hline Croton sublyratus Kurz & $4.73 \pm 0.38$ & $6.74 \pm 0.51$ & $16.28 \pm 0.29$ & $18.55 \pm 0.53$ & $20.78 \pm 1.49$ & $14.86 \pm 0.95$ \\
\hline Datura metel L. & $8.30 \pm 0.29$ & $11.43 \pm 0.17$ & $18.92 \pm 1.50$ & $17.65 \pm 1.62$ & $16.77 \pm 1.30$ & $2.04 \pm 0.16$ \\
\hline Garcinia mangostana Linn. & $19.75 \pm 1.44$ & $31.07 \pm 2.30$ & $80.79 \pm 2.94$ & $5.35 \pm 0.10$ & $11.13 \pm 0.37$ & $3.20 \pm 0.05$ \\
\hline Gynura pseudochina (L.) DC. & $3.26 \pm 0.11$ & $9.18 \pm 0.65$ & $12.76 \pm 0.81$ & $4.87 \pm 0.35$ & $18.60 \pm 1.06$ & $3.69 \pm 0.21$ \\
\hline Hibiscus mutabilis L. & $3.44 \pm 0.14$ & $7.14 \pm 0.48$ & $17.05 \pm 0.64$ & $3.71 \pm 0.24$ & $18.79 \pm 1.78$ & $3.71 \pm 0.09$ \\
\hline Ipomoea pes-caprae (L.) R.br. & $4.72 \pm 0.29$ & $11.18 \pm 0.53$ & $37.91 \pm 3.36$ & $27.48 \pm 2.59$ & $18.68 \pm 0.66$ & $17.66 \pm 0.29$ \\
\hline Phyllanthus acidus (L.) Skeels & $4.65 \pm 0.46$ & $10.05 \pm 0.74$ & $50.52 \pm 2.66$ & NA & $15.80 \pm 1.04$ & $11.74 \pm 0.74$ \\
\hline Rhinacanthus nasutus (L.) Kurz & $5.04 \pm 0.30$ & $9.14 \pm 0.39$ & $17.09 \pm 1.44$ & $16.98 \pm 0.40$ & $19.88 \pm 1.98$ & $9.53 \pm 0.26$ \\
\hline Senna alata (L.) Roxb. & $4.59 \pm 0.21$ & $9.48 \pm 0.44$ & $36.83 \pm 2.30$ & $7.71 \pm 0.36$ & $13.97 \pm 1.10$ & $31.38 \pm 0.81$ \\
\hline Stemona curtisii Hook.f. & $2.51 \pm 0.22$ & $7.76 \pm 0.30$ & $59.67 \pm 3.28$ & NA & NA & $14.50 \pm 0.86$ \\
\hline Streblus asper Lour. & $4.19 \pm 0.30$ & $8.22 \pm 0.39$ & $23.10 \pm 1.84$ & NA & $18.66 \pm 1.28$ & $11.29 \pm 1.04$ \\
\hline
\end{tabular}

Each value is mean \pm S.D. of triplicate independent analyses. GAE Gallic Acid Equivalent, QE Quercitin equivalent, NA Not Available 


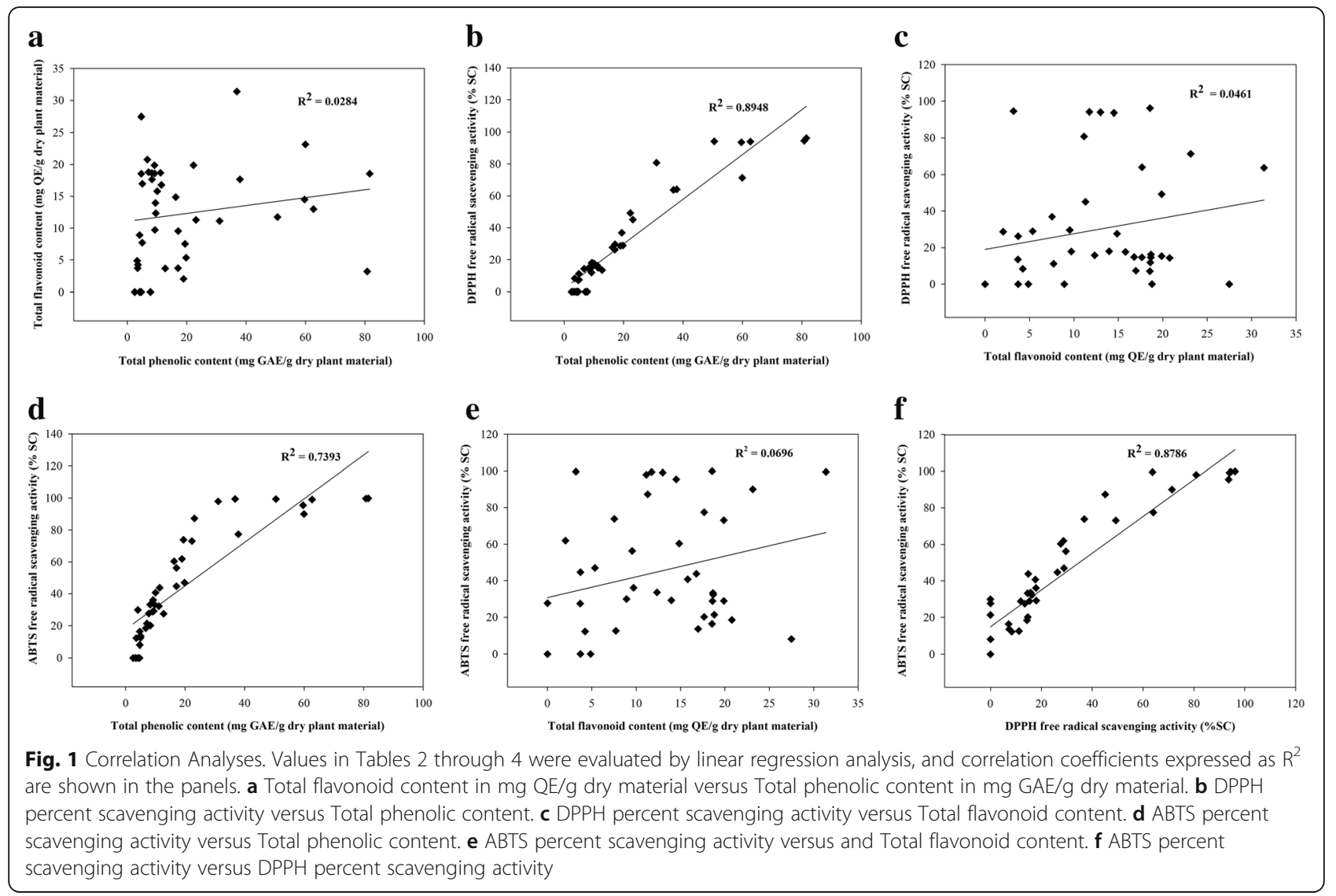

Table 3 Free Radical Scavenging activity by DPPH assay

\begin{tabular}{|c|c|c|c|c|c|c|}
\hline \multirow[t]{2}{*}{ Extract } & \multicolumn{3}{|c|}{ Percent Scavenging Activity (\%) } & \multicolumn{3}{|c|}{ mg VCEAC/g dry weight } \\
\hline & Petroleum ether & Dichloromethane & Ethanol & Petroleum ether & Dichloromethane & Ethanol \\
\hline Annona squamosa $\mathrm{L}$. & NA & $17.91 \pm 0.88$ & $94.01 \pm 0.40$ & NA & $3.08 \pm 0.29$ & $23.60 \pm 0.62$ \\
\hline Ardisia elliptica Thunb. & $49.29 \pm 1.29$ & $71.35 \pm 6.11$ & $96.17 \pm 0.05$ & $12.09 \pm 0.94$ & $20.23 \pm 0.99$ & $24.93 \pm 0.19$ \\
\hline Croton roxburghii N.P.Balakr & $8.34 \pm 0.57$ & $15.79 \pm 1.21$ & $36.89 \pm 1.37$ & $1.03 \pm 0.09$ & $2.38 \pm 0.13$ & $8.45 \pm 0.84$ \\
\hline Croton sublyratus Kurz & $7.11 \pm 0.59$ & $14.34 \pm 0.65$ & $27.64 \pm 0.91$ & $0.67 \pm 0.07$ & $1.85 \pm 0.06$ & $5.29 \pm 0.30$ \\
\hline Datura metel L. & $14.67 \pm 1.10$ & $14.85 \pm 0.64$ & $28.72 \pm 0.67$ & $2.00 \pm 0.12$ & $2.30 \pm 0.06$ & $5.83 \pm 0.26$ \\
\hline Garcinia mangostana Linn. & $28.90 \pm 0.99$ & $80.87 \pm 0.47$ & $94.54 \pm 0.15$ & $6.18 \pm 0.33$ & $20.42 \pm 0.20$ & $24.28 \pm 0.20$ \\
\hline Gynura pseudochina (L.) DC. & NA & $11.90 \pm 0.71$ & $13.54 \pm 0.67$ & NA & $1.49 \pm 0.03$ & $1.82 \pm 0.13$ \\
\hline Hibiscus mutabilis L. & NA & NA & $26.28 \pm 0.93$ & NA & NA & $4.29 \pm 0.21$ \\
\hline Ipomoea pes-caprae (L.) R.br. & NA & $16.27 \pm 0.14$ & $64.06 \pm 1.23$ & NA & $2.49 \pm 0.19$ & $16.79 \pm 0.41$ \\
\hline Phyllanthus acidus (L.) Skeels & NA & $17.64 \pm 1.05$ & $94.17 \pm 0.61$ & NA & $3.06 \pm 0.28$ & $23.84 \pm 0.73$ \\
\hline Rhinacanthus nasutus (L.) Kurz & $7.38 \pm 0.46$ & $15.35 \pm 1.27$ & $29.63 \pm 1.41$ & $1.01 \pm 0.08$ & $2.32 \pm 0.21$ & $6.50 \pm 0.16$ \\
\hline Senna alata (L.) Roxb. & $11.18 \pm 0.99$ & $17.99 \pm 0.61$ & $63.74 \pm 0.54$ & $1.48 \pm 0.14$ & $3.13 \pm 0.31$ & $15.35 \pm 0.13$ \\
\hline Stemona curtisii Hook.f. & NA & NA & $93.63 \pm 0.22$ & NA & NA & $23.55 \pm 0.55$ \\
\hline Streblus asper Lour. & NA & $14.65 \pm 0.92$ & $45.14 \pm 0.67$ & NA & $1.94 \pm 0.13$ & $10.45 \pm 0.30$ \\
\hline
\end{tabular}

Each value is mean \pm S.D. of triplicate independent analyses. Calculations of values are described in the Materials and Methods section. VCEAC is Vitamin C Equivalent Antioxidant capacity, and NA denotes not available 
in the petroleum ether fraction. No scavenging activity was detected in 7 petroleum ether extracts, and 2 dichloromethane extracts.

\section{ABTS radical scavenging activity in different extracts from 14 Thai plants}

Antioxidant activity of aqueous and lipid phases in the plants has also been evaluated by a decolorization assay using ABTS [13]. Again, ascorbic acid served as the standard antioxidant. As with the DPPH assay, scavenging activity in the ABTS assay varied greatly among the plant preparations with a similar broad range from $8.03 \pm 0.54 \%$ to $99.84 \pm 0.07 \%$ (Table 4). Furthermore, the next strongest scavenging activities (>90\%) were observed in the same 4 ethanol fractions as shown by the DPPH assay. In addition, no scavenging activity was found in the same 5 petroleum ether extracts. In general, the values obtained with the ABTS assay were higher than the DPPH values. Hence, activity in the ethanol extract from Senna alata (L.) Roxb. was now observed as $>90 \%$, and scavenger activity was detected in all dichloromethane extracts, and petroleum ether extracts from Annona squamosa L. and Ipomoea pes-caprae (L.) R.br. which was not detected by the DPPH assay.

\section{Tyrosinase activity inhibition by plant extracts}

The ability of compounds from the Thai plants to inhibit mushroom tyrosinase activity was evaluated using an in vitro assay with L-DOPA as the substrate. Kojic acid served as a known inhibitor, and caused maximal enzymatic inhibition of $93.38 \pm 1.63 \%$. As shown in Table 5, only ethanol extracts significantly inhibited tyrosinase activity, with Ardisia elliptica Thunb. preparations being the exception. The petroleum ether and dichloromethane fractions of Ardisia elliptica Thunb. inhibited tyrosinase activity by approximately $20 \%$. The ethanol fraction from Rhinacanthus nasutus (L.) Kurz (IC 50 value of $271.50 \mu \mathrm{g} / \mathrm{ml}$ ) was the most potent tyrosinase inhibitor, followed by the ethanol extracts from Ardisia elliptica Thunb. and Phyllanthus acidus (L.) Skeels. Other ethanol fractions significantly decreased enzymatic activity by more than 20\% (Table 5), whereas the remaining extracts did not have detectable inhibitory activity (data not shown).

\section{Collagenase activity inhibition by 14 plants}

Extracts were tested for anti-collagenase activity using Clostridium histolyticum collagenase, and N-[3-(2-furyl)acryloyl]-Leu-Gly-Pro-Ala (FALGPA) as the substrate. Epigallatecatechin gallate is a known collagenase inhibitor, and decreased enzymatic activity by $90.51 \pm 2.79 \%$. As shown in Table 5, only 4 ethanol extracts contained detectable collagenase inhibitory activity. Of those causing inhibition, Ardisia elliptica Thunb. (IC 50 value of $157.78 \mu \mathrm{g} / \mathrm{ml}$ ) exhibited the highest level of collagenase inhibition, followed by Annona squamosa L. (IC 50 value of $426.67 \mu \mathrm{g} / \mathrm{ml}$ ), Senna alata (L.) Roxb., and Croton sublyratus Kurz in rank order. Other plant extracts did not significantly inhibit collagenase activity under the reaction conditions utilized in this study (data not shown).

\section{Discussion}

Solar radiation is a significant environmental factor in skin damage and can induce skin cancer [14]. UV radiation causes a pro-inflammatory response, extracellular matrix degradation and antioxidant depletion $[15,16]$. UV causes

Table 4 Scavenging activity by ABTS assay

\begin{tabular}{|c|c|c|c|c|c|c|}
\hline \multirow[t]{2}{*}{ Extract } & \multicolumn{3}{|c|}{ \%Scavenging activity (\%SC) } & \multicolumn{3}{|c|}{ mg VCEAC/g dry weight } \\
\hline & Petroleum ether & Dichloromethane & Ethanol & Petroleum ether & Dichloromethane & Ethanol \\
\hline Annona squamosa $\mathrm{L}$. & $29.89 \pm 0.79$ & $36.31 \pm 0.60$ & $99.13 \pm 0.29$ & $25.76 \pm 0.76$ & $34.40 \pm 0.32$ & $96.15 \pm 0.38$ \\
\hline Ardisia elliptica Thunb. & $73.08 \pm 1.48$ & $90.01 \pm 0.54$ & $99.84 \pm 0.07$ & $65.28 \pm 1.86$ & $86.34 \pm 1.07$ & $96.97 \pm 0.34$ \\
\hline Croton roxburghii N.P.Balakr & $12.19 \pm 0.91$ & $33.54 \pm 0.65$ & $73.86 \pm 1.22$ & $9.14 \pm 0.45$ & $33.22 \pm 0.46$ & $69.62 \pm 0.90$ \\
\hline Croton sublyratus Kurz & $16.34 \pm 0.69$ & $18.47 \pm 0.73$ & $60.36 \pm 0.17$ & $13.07 \pm 1.29$ & $17.81 \pm 1.20$ & $58.62 \pm 0.68$ \\
\hline Datura metel L. & $20.17 \pm 0.68$ & $43.79 \pm 0.89$ & $61.94 \pm 0.50$ & $16.42 \pm 0.65$ & $42.36 \pm 1.11$ & $60.06 \pm 0.16$ \\
\hline Garcinia mangostana Linn. & $47.01 \pm 2.73$ & $97.96 \pm 0.85$ & $99.66 \pm 0.05$ & $45.10 \pm 2.45$ & $95.19 \pm 1.43$ & $96.52 \pm 0.34$ \\
\hline Gynura pseudochina (L.) DC. & NA & $28.88 \pm 0.45$ & $27.52 \pm 1.66$ & NA & $28.00 \pm 0.36$ & $25.37 \pm 1.99$ \\
\hline Hibiscus mutabilis L. & NA & $21.36 \pm 0.51$ & $44.74 \pm 0.23$ & NA & $20.34 \pm 0.42$ & $43.29 \pm 1.26$ \\
\hline Ipomoea pes-caprae (L.) R.br. & $8.03 \pm 0.54$ & $32.30 \pm 1.93$ & $77.43 \pm 1.74$ & $4.53 \pm 0.34$ & $31.41 \pm 2.73$ & $75.16 \pm 2.37$ \\
\hline Phyllanthus acidus (L.) Skeels & NA & $40.72 \pm 1.25$ & $99.43 \pm 0.17$ & NA & $40.06 \pm 1.90$ & $96.27 \pm 0.10$ \\
\hline Rhinacanthus nasutus (L.) Kurz & $13.55 \pm 0.49$ & $28.90 \pm 0.57$ & $56.26 \pm 0.90$ & $10.60 \pm 0.24$ & $28.29 \pm 1.77$ & $53.26 \pm 1.95$ \\
\hline Senna alata (L.) Roxb. & $12.51 \pm 0.41$ & $29.21 \pm 1.35$ & $99.45 \pm 0.11$ & $8.79 \pm 0.17$ & $28.97 \pm 0.56$ & $96.28 \pm 0.12$ \\
\hline Stemona curtisii Hook.f. & NA & $27.65 \pm 1.30$ & $95.49 \pm 0.25$ & NA & $27.48 \pm 0.11$ & $91.91 \pm 0.63$ \\
\hline Streblus asper Lour. & NA & $33.22 \pm 0.77$ & $87.32 \pm 0.39$ & NA & $32.92 \pm 1.57$ & $83.78 \pm 0.90$ \\
\hline
\end{tabular}

Each value is mean \pm S.D. of triplicate independent analyses. Calculations of values are described in the Materials and Methods section. VCEAC Vitamin C Equivalent Antioxidant capacity, NA not available 
Table 5 Inhibition of tyrosinase and collagenase activities by Thai plant extracts

\begin{tabular}{llll}
\hline Plant & Extract & Tyrosinase inhibition (\%) & Collagenase inhibition(\%) \\
\hline Annona squamosa Linn. & Ethanol & $21.92 \pm 1.45^{* *}$ & $55.12 \pm 3.18^{* * *}$ \\
Ardisia elliptica Thunb. & Petroleum ether & $19.42 \pm 1.21^{* *}$ & $\mathrm{NA}$ \\
Ardisia elliptica Thunb. & Dichloromethane & $21.40 \pm 1.61^{* *}$ & $\mathrm{NA}$ \\
Ardisia elliptica Thunb. & Ethanol & $49.54 \pm 1.23^{* * *}$ & $94.88 \pm 6.93^{* * *}$ \\
Croton sublyratus Kurz & Ethanol & $\mathrm{NA}$ & $24.14 \pm 0.98^{* *}$ \\
Datura metel L. & Ethanol & $20.91 \pm 1.70^{* *}$ & $\mathrm{NA}$ \\
Ipomoea pes-caprae (L.) R.br. & Ethanol & $23.01 \pm 1.65^{* *}$ & $\mathrm{NA}$ \\
Phyllanthus acidus (L.) Skeels. & Ethanol & $42.92 \pm 3.85^{* * *}$ & $\mathrm{NA}$ \\
Rhinacanthus nasutus (L.) Kurz & Ethanol & $64.68 \pm 5.46^{* * *}$ & $\mathrm{NA}$ \\
Senna alata (L.) Roxb. & Ethanol & $23.49 \pm 1.09^{* *}$ & $41.49 \pm 2.63^{* * *}$ \\
Kojid acid (tyrosinase inhibitor) & & $93.38 \pm 1.63^{* * *}$ & \\
Epigallatecathechin gallate & & - & $90.51 \pm 2.79^{* * *}$
\end{tabular}

Each value is mean \pm S.D. of triplicate independent analyses. Significantly different from the control group

$\left({ }^{*} P<0.05,{ }^{* *} P<0.01,{ }^{* * *} P<0.001\right)$. NA not available

formation of reactive oxygen species (ROS) that induce hyperpigmentation and collagenase expression [17, 18]. Our study investigated 14 Thai plants extracted with three different solvents for their potential as anti-wrinkle and skin whitening ingredients. In this study, we used petroleum ether, dichloromethane and ethanol for plant extraction using Soxhlet apparatus. Ardisia elliptica Thunb. had the highest yield in the petroleum ether and ethanol extracts, whereas Garcinia mangostana L. had the highest percent yield from dichloromethane extraction. These solvents are a series of organic solvents with increasing polarities. Variation among the percent yields depended on the plant species, and probably reflected differences in chemical composition of the plants.

Phenolics are the largest group of phytochemicals found in plants and they have various biological activities in animals, including humans [19]. Total phenolic content in the plants was determined by the FolinCiocalteu method. Overall, the ethanol fraction had the richest phenolic content, followed by dichloromethane, while petroleum ether with low polarity had the lowest phenolic content compared to the other solvents. In this study, Ardisia elliptica Thunb. had the highest phenolic content in all three types of extracts. In previous studies, dichloromethane leaf extracts of Ardisia elliptica Thunb. have a phenolic content of $101 \pm 1.3 \mathrm{mg}$ GAE per g dry plant material, which is more than the content in a twig extract [20]. Moreover, a methanol extract of ripe Ardisia fruit contained $5.64 \pm 0.37 \mathrm{~g}$ GAE per $100 \mathrm{~g}$ extract [21]. Hence, leaves and fruits of Ardisia elliptica Thunb. have a high phenolic content that can be easily extracted with methanol, dichloromethane and ethanol.

Flavonoids are pigments in flowers, leaves, fruits and seeds. These compounds are secondary metabolites of plants and are widely distributed among plant species [22] Next, the flavonoid content within the Thai plants was evaluated using the aluminium chloride colorimetric assay. Our results showed that the highest flavonoid quantity was found in the ethanol extract from Senna alata (L.) Roxb leaves. In a previous study, high flavonoid content was found in water ( $4.25 \mathrm{mg}$ QE per $100 \mathrm{~g}$ ) and methanol fractions (3.97 mg QE per $100 \mathrm{~g}$ ) of Senna alata (L.) Roxb. [23]. Thus, Senna alata (L.) Roxb preparations have a high flavonoid content when extracted with high polarity solvents including ethanol, methanol and water. Ardisia elliptica Thunb. had the richest flavonoid content in the dichloromethane fraction. Fruit of this plant also has a high flavonoid content $36.91 \pm 2.37 \mathrm{mg}$ QE per g extract [24]. Hence, fruit and leaves of Ardisia elliptica Thunb. are rich in flavonoids. Total flavonoid content did not correlate with total phenolic content. However, flavonoids have many biological activities such as UVB protection [25], anti inflammatory [26], anti-hepatotoxicity [27] and anti cancer [28].

Free radical scavenging activity using DPPH and ABTS assay. In the DPPH assay, DPPH receives a hydrogen atom from an antioxidant [29]. We found that Ardisia elliptica Thunb ethanol extract had the highest scavenging activity. Other investigators have also reported that dichloromethane fractions of Ardisia elliptica Thunb. leaves and stems have high levels of antioxidant activity as determined by the DPPH assay, and, hence, this plant is very interesting to investigate further as a herbal treatment [20]. The extracts from the ethanol fraction with high polarity clearly showed better antioxidant activity than fractions with lower polarities containing dichloromethane and petroleum ether. Ethanol extracts contained the highest levels of free radical scavenging activity compared with the other extracts, and all ethanol extracts were 
active. In the ABTS assay, ABTS is converted to its radical cation by the addition of potassium persulfate. In the presence of an antioxidant, the reactive ABTS cation (or ABTS ${ }^{\circ}$ $\left.{ }^{+}\right)$is converted to its colorless natural form [9]. In agreement with the DPPH assay, ethanol extracts contained the highest levels of scavenger activity as compared with the other extracts. Again, the highest scavenging activities in ethanol, dichloromethane and petroleum ether extracts were from the same plants as shown by the DPPH assay. The results of the DPPH and ABTS assays were highly correlated as expected (Fig. 1f).

However, total flavonoid content of the plant extracts did not correlate with free radical scavenger activity as detected by the DPPH assay (Fig. 1c) or by the ABTS assay (Fig. 1e). Our findings of no significant relationship between flavonoid content and scavenger activity using the ABTS assay is consistent with other investigators' results [30]. By contrast, total phenolic content of the plant preparation positively correlated with scavenger activity measured by both assays (Fig. $1 \mathrm{~b}$ and d) in agreement with a previous study [31]. Noticeably, the scavenging activity depended on total phenolic content and solvents with high polarity, such as ethanol and dichloromethane. These results suggest that the phenolic content is the major constituent with antioxidant activity in the 14 Thai plants.

Melanin, the major pigment of skin and hair color, is synthesized by melanocytes within melanosomes. Overproduction and accumulation of melanin in skin may lead to pigmentary disorders and aesthetic problems. Hyperpigmentation occurs in sun-exposed areas of the skin [32]. In the melanogenesis, tyrosinase is the key enzyme in the ratelimiting step in which L-tyrosine is hydroxylated to LDOPA, which is further oxidized into DOPAquinone. After that, it is converted into DOPAchrome that is a substrate for melanin synthesis [3]. Downregulation of tyrosinase activity has been proposed to be responsible for decreased melanin production. The development of novel whitening phytochemical compounds from natural products has recently become a growing trend. Our finding showed that the ethanol fraction from Rhinacanthus nasutus (L.) Kurz was the most potent tyrosinase inhibitor, followed by the ethanol extracts from Ardisia elliptica Thunb. and Phyllanthus acidus (L.) Skeels. Obviously, 7 plants from 14 plants had the high phenolic content, especially Ardisia elliptica Thunb. and Annona squamosa L.. Moreover, Senna alata (L.) Roxb. had the richest flavonoid content which can inhibit tyrosinase activity. Active compounds from the plants such as arbutin, aloesin, gentisic acid, flavonoids, hesperidin, licorice, niacinamide, yeast derivatives, and polyphenols, can inhibit melanogenesis without cytotoxicity to melanocytes [6].

Collagenase is a transmembrane zinc peptidase that cleaves the X-Gly bond of collagen. Collagen is an abundant structural protein and extracellular matrix component [33]. Decreased collagen and elastin fibers increases with age and damage from UV radiation inducing wrinkled skin [34]. Collagenase inhibition has been proposed to prevent skin aging. Of those causing inhibition in our study, Ardisia elliptica Thunb. exhibited the highest level of collagenase inhibition, followed by Annona squamosa L., Senna alata (L.) Roxb., and Croton sublyratus Kurz in rank order. In a previous study, cocoa pod extract had phenolic acid and flavonoids that inhibited elastase and collagenase activity [35]. Notably, three ethanol extracts (Ardisia elliptica Thunb., Annona squamosa L. and Senna alata (L.) Roxb. inhibited both tyrosinase and collagenase. These plants also had high phenolic and flavonoid levels, and antioxidant activity. Interestingly, these extracts have possible uses as ingredients for cosmetic products.

\section{Conclusion}

Our results demonstrate that extracts of 14 Thai plants had varying degrees of total phenolic and flavonoid content as well as free radical scavenging activities, depending on the extraction solvents. There was a high correlation between total phenolic content and free radical scavenging activity ass assessed by the DPPH and ABTS assays. The ethanol fraction of Ardisia elliptica Thunb. had the highest phenolic content, followed by Annona squamosa L. Both plants significantly inhibited tyrosinase and collagenase activities, while Rhinacanthus nasutus (L.) Kurz showed the highest tyrosinase inhibition. Moreover, Senna alata (L.) Roxb. was richest in flavonoid content, and also exhibited tyrosinase and collagenase inhibitory behavior. The ethanol fraction of three plants, namely Annona squamosa L., Ardisia elliptica Thunb and Senna alata (L.) Roxb., have the potential to be ingredients in cosmetic products for antiwrinkling as well as skin whitening. Further studies are necessary to investigate the active components and safety of these extracts.

\section{Abbreviations \\ ABTS: 2,2-Azino-bis(3-ethylbenzthiazoline-6-sulphonic acid); DHI: 5,6- dihydroxyindole (DHI); DHICA: 5,6-dihydroxyindole-2-carboxylic acid; DMSO: Dimethyl sulfoxide; DPPH: 2,2-diphenyl-1-picrylhydrazyl; \\ EGCG: Epigallocatechin gallate; FALGPA: N-[3-(2-furyl) acryloyl]-Leu-Gly-Pro-Ala; GAE: Gallic acid equivalents; KA: Kojic acid; L-DOPA: 3,4-dihidroxyphenyl alanine; $\mathrm{Na}_{2} \mathrm{CO}_{3}$ : Sodium carbonate; QE: Quercetin equivalents; ROS: Reactive oxygen species; SC: Scavenging activity; TFC: Total flavonoid content; TPC: Total phenolic content; UVR: Ultraviolet radiation; VCEAC: Vitamin C equivalent antioxidant capacity}

\section{Acknowledgements}

We are grateful to the Center for Excellence in Omics-Nano Medical Technology Development Project and the Innovation Center for Research, Development of Medical Diagnostic Technology Project. We appreciate the assistance of the $\mathrm{HRH}$ Princess Sirindhorn Herb Garden to give the plants for this project. We thank Waluga Plaingam as a technical assistant. We would like to express our gratitude to Prof. Dr. Kathleen L. McCoy (Department of Microbiology and Immunology, School of Medicine, Virginia Commonwealth University), who was financially supported by the grant for foreign academics and researchers to 
increase published articles in international journals through the Chulalongkorn University Ratchadaphiseksomphot Endowment Fund 2015 for her critical reading of this manuscript. Finally, we would like to express our gratitude to Prof. Dr. Duncan R. Smith (Institute of Molecular Biosciences, Mahidol University) for his critical reading and reviewing of this manuscript.

\section{Funding}

This study was supported financially by the 100th Year Chulalongkorn University Fund for doctoral scholarship and the Research fund project 58,002, Faculty of Allied Health Sciences, Chulalongkorn University, Thailand. This research was also supported by the National Research University Project, Office of Higher Education Commission (NRU59-007-HR).

\section{Availability of data and materials}

Not applicable since all the data supporting the results reported are in this manuscript.

\section{Authors' contributions}

$M C$ and $A C$ designed hypothesis and supervised experiments. MC performed the experiments in this study, analyzed the data and drafted the manuscript. AC assisted with analyzing the data, drafting and revising the manuscript. All authors read and approved the final manuscript.

\section{Ethics approval and consent to participate}

This information is not relevant since our study does involve neither animals nor humans.

\section{Consent for publication}

Not applicable since our manuscript does not contain any individual person's data in any form.

\section{Competing interests}

The authors declare that they have no competing interests.

\section{Publisher's Note}

Springer Nature remains neutral with regard to jurisdictional claims in published maps and institutional affiliations.

\section{Author details}

'Program in Clinical Biochemistry and Molecular Medicine, Department of Clinical Chemistry, Faculty of Allied Health Sciences, Chulalongkorn University, Bangkok, Thailand. 'Department of Clinical Chemistry, Faculty of Allied Health Sciences, Chulalongkorn University, Bangkok 10330, Thailand.

Received: 30 May 2017 Accepted: 1 November 2017

Published online: 09 November 2017

\section{References}

1. Moehrle M. Outdoor sports and skin cancer. Clin Dermatol. 2008;26(1):12-5.

2. Lopez-Camarillo C, Ocampo EA, Casamichana ML, Perez-Plasencia C, Alvarez-Sanchez E, Marchat LA. Protein kinases and transcription factors activation in response to UV-radiation of skin: implications for carcinogenesis. Int J Mol Sci. 2012:13(1):142-72.

3. Iwata M, Corn T, Iwata S, Everett MA, Fuller BB. The relationship between tyrosinase activity and skin color in human foreskins. J Investig Dermatol. 1990;95(1):9-15

4. Stern RS. Treatment of Photoaging. N Engl J Med. 2004:350(15):1526-34.

5. Levin $\mathrm{CY}$, Maibach $\mathrm{H}$. Exogenous ochronosis. An update on clinical features, causative agents and treatment options. Am J Clin Dermatol. 2001;2(4):213-7.

6. Zhu W, Gao J. The use of botanical extracts as topical skin-lightening agents for the improvement of skin pigmentation disorders. J Investig Dermatol Symp Proc. 2008;13(1):20-4

7. Zongo C, Savadogo A, Ouattara L, Bassole IHN, Ouattara CAT, Ouattara AS, Barro N, Koudou J, Traorel AS. Polyphenols content, antioxidant and antimicrobial activities of Ampelocissus grantii (baker) Planch. (Vitaceae): a medicinal plant from Burkina Faso. Int J Pharmacol. 2010;6(880-887)

8. Yamasaki K, Hashimoto A, Kokusenya Y, Miyamoto T, Sato T. Electrochemical method for estimating the antioxidative effects of methanol extracts of crude drugs. Chem Pharm Bull (Tokyo). 1994;42(8):1663-5.
9. Re R, Pellegrini N, Proteggente A, Pannala A, Yang M, Rice-Evans C. Antioxidant activity applying an improved ABTS radical cation decolorization assay. Free Radic Biol Med. 1999;26(9-10):1231-7.

10. Nithitanakool S, Pithayanukul P, Bavovada R, Saparpakorn P. Molecular docking studies and anti-tyrosinase activity of Thai mango seed kernel extract. Molecules. 2009;14(1):257-65.

11. Bonvicini F, Antognoni F, lannello C, Maxia A, Poli F, Gentilomi GA. Relevant and selective activity of Pancratium Illyricum L. against Candida Albicans clinical isolates: a combined effect on yeast growth and virulence. BMC Complement Altern Med. 2014;14(1):409.

12. Sharma OP, Bhat TK. DPPH antioxidant assay revisited. Food Chem. 2009. 113(4):1202-5

13. MacDonald-Wicks LK, Wood LG, Garg ML. Methodology for the determination of biological antioxidant capacity in vitro: a review. J Sci Food Agric. 2006; 86(13):2046-56.

14. Armstrong BK, Kricker A. The epidemiology of UV induced skin cancer. J Photochem Photobiol B Biol. 2001:63(1-3):8-18.

15. Bashir MM, Sharma MR, Werth VP. UVB and pro-inflammatory cytokines synergistically activate TNF-a production in keratinocytes through enhanced gene transcription. J Investig Dermatol. 2009;129(4):994-1001.

16. Watson RE, Gibbs NK, Griffiths CE, Sherratt MJ. Damage to skin extracellular matrix induced by UV exposure. Antioxid Redox Signal. 2014:21(7):1063-77.

17. D'Orazio J, Jarrett S, Amaro-Ortiz A, Scott T. UV radiation and the skin. Int J Mol Sci. 2013;14(6):12222-48.

18. Pittayapruek P, Meephansan J, Prapapan O, Komine M, Ohtsuki M. Role of matrix Metalloproteinases in Photoaging and Photocarcinogenesis. Int J Mol Sci. 2016;17(6):868

19. Sulaiman CT, Balachandran I. Total phenolics and total flavonoids in selected Indian medicinal plants. Indian J Pharm Sci. 2012;74(3):258-60.

20. Mamat N, Jamal JA, Jantan I, Husain K. Xanthine Oxidase inhibitory and DPPH radical scavenging activities of some Primulaceae species. Sains Malaysiana. 2014;43(12):1827-33.

21. Wetwitayaklung $P$, Charoenteeraboon J, Limmatvapirat C, Phaechamud T. Antioxidant activities of some Thai and exotic fruits cultivated in Thailand Res J Pharm, Biol Chem Sci. 2012:3(1):12-21.

22. Falcone Ferreyra ML, Rius SP, Casati P. Flavonoids: biosynthesis, biological functions, and biotechnological applications. Front Plant Sci. 2012;3:222.

23. Devendra K, Kiran D, Ritesh V, Satyendra B, Abhishek K. To evaluation of Total Phenolics and Flavonoids in different Plant of Chhattisgarh. J Pharmacognosy Phytochem. 2013;2(4):116-8.

24. Siti-Azima AM, Noriham A, Nurhuda M. Antioxidant activities of Syzygium Cumini and ArdisiaElliptica in relation to their estimated Phenolic compositions and chromatic properties. Int J Biosci Biochem Bioinform. 2013;3(4):314-7.

25. Solovchenko A, Schmitz-Eiberger M. Significance of skin flavonoids for UV-Bprotection in apple fruits. J Exp Bot. 2003;54(389):1977-84.

26. Gonzalez-Gallego J, Sanchez-Campos S, Tunon MJ. Anti-inflammatory properties of dietary flavonoids. Nutr Hosp. 2007;22(3):287-93.

27. Sudha A, Sumathi K, Manikandaselvi S, Prabhu NM, Srinivasan P. Antihepatotoxic activity of crude Flavonoid fraction of Lippia Nodiflora L. on ethanol induced liver injury in rats. Asian J Anim Sci. 2013:7(1):1-13.

28. Sak K. Cytotoxicity of dietary flavonoids on different human cancer types. Pharmacogn Rev. 2014;8(16):122-46.

29. Kedare SB, Singh RP. Genesis and development of DPPH method of antioxidant assay. J Food Sci Technol. 2011;48(4):412-22.

30. Boo H-O, Kim T-S, Koshio K, Shin J-H, Chon S-U. Total Phenolics levels and antioxidant properties in methanol extracts from several Vietnamese wild plants. Korean J Plant Res. 2011:24(6):659-65.

31. Dudonne S, Vitrac X, Coutiere P, Woillez M, Merillon JM. Comparative study of antioxidant properties and total phenolic content of 30 plant extracts of industrial interest using DPPH, ABTS, FRAP, SOD, and ORAC assays. J Agric Food Chem. 2009:57(5):1768-74.

32. Slominski A, Tobin DJ, Shibahara S, Wortsman J. Melanin pigmentation in mammalian skin and its hormonal regulation. Physiol Rev. 2004;84(4):1155-228.

33. Shoulders MD, Raines RT. Collagen structure and stability. Annu Rev Biochem. 2009;78:929-58.

34. Cua AB, Wilhelm KP, Maibach HI. Elastic properties of human skin: relation to age, sex, and anatomical region. Arch Dermatol Res. 1990;282(5):283-8.

35. Karim AA, Azlan A, Ismail A, Hashim P, Gani SSA, Zainudin BH, Abdullah NA Phenolic composition, antioxidant, anti-wrinkles and tyrosinase inhibitory activities of cocoa pod extract. BMC Complement Altern Med. 2014;14(381): $1-13$. 